\title{
Switching to olanzapine long-acting injection from either oral olanzapine or any other antipsychotic: comparative post hoc analyses
}

This article was published in the following Dove Press journal:

Neuropsychiatric Disease and Treatment

7 November 2013

Number of times this article has been viewed

\author{
Antonio Ciudad' \\ Ernie Anand ${ }^{2}$ \\ Lovisa Berggren ${ }^{3}$ \\ Marta Casillas ${ }^{4}$ \\ Alexander Schacht ${ }^{3}$ \\ Elena Perrin ${ }^{5}$ \\ 'Department of Clinical Research \\ and Development, Eli Lilly \& Co, \\ Madrid, Spain; ${ }^{2}$ Neuroscience Medical \\ Affairs - EU, Lilly Research Centre, \\ Windlesham, Surrey, UK; ${ }^{3}$ Global \\ Statistical Sciences, Eli Lilly \& Co, \\ Bad Homburg, Germany; ${ }^{4}$ European \\ Scientific Communications, Eli \\ Lilly \& Co, Madrid, Spain; ${ }^{5}$ Medical \\ Department, Eli Lilly \& Co, Suresnes, \\ Paris, France
}

Background: A considerable proportion of patients suffering from schizophrenia show suboptimal responses to oral antipsychotics due to inadequate adherence. Hence, they are likely to benefit from switching to a long-acting injectable formulation. These post hoc analyses assessed the clinical effects of switching to olanzapine long-acting injection (OLAI) from either oral olanzapine (OLZ) or other antipsychotics (non-OLZ).

Methods: Post hoc analyses were done based on two randomized studies (one short-term, one long-term) conducted in patients suffering from schizophrenia and treated with OLAI. The short-term study was an 8-week placebo-controlled, double-blind trial in acute patients, and the long-term study was a 2-year, oral olanzapine-controlled, open-label, follow-up of stabilized outpatients.

Results: These analyses used data from 62 OLAI-treated patients (12 switched from OLZ, 50 from non-OLZ) from the short-term study and 190 OLAI-treated patients ( 56 switched from OLZ, 134 from non-OLZ) from the long-term study. Kaplan-Meier survival analyses of time to all-cause discontinuation of OLAI treatment did not differ significantly between OLZ and non-OLZ patients in the short-term study $(P=0.209)$ or long-term study $(P=0.448)$. Similarly, the proportions of OLZ and non-OLZ patients that discontinued OLAI were not statistically different in the short-term ( $16.7 \%$ versus $36.0 \%$, respectively; $P=0.198)$ or long-term $(57.1 \%$ versus $47.8 \%$ respectively; $P=0.238$ ) studies. In the short-term study, no significant differences were detected between the patient groups in mean change in Positive and Negative Syndrome Scale (PANSS) total score ( -13.4 OLZ versus -20.8 non-OLZ; $P=0.166)$. In the long-term study, mean change in PANSS total score ( 3.9 OLZ versus -3.6 non-OLZ; $P=0.008$ ) was significantly different between the non-OLZ and OLZ groups. Rates of treatment-emergent adverse events were similar in OLZ and non-OLZ groups per study.

Conclusion: These post hoc analyses suggest that no significant differences in clinical effectiveness were seen after switching from non-OLZ or OLZ to OLAI. However, these findings should be interpreted with care, due to small sample sizes and differences in patients' clinical profiles.

Keywords: schizophrenia, olanzapine, long-acting injection, depot formulation

\section{Introduction}

Long-term treatment with antipsychotic medication is a mainstay therapeutic approach in patients with schizophrenia. However, partial or total nonadherence to oral antipsychotic therapy continues to be a major problem in the long-term management of the disease, ${ }^{1}$ affecting approximately $50 \%$ of patients. ${ }^{2,3}$ Antipsychotic nonadherence often leads to negative outcomes, including symptom exacerbation, relapse, more emergency room admissions, and rehospitalizations. ${ }^{4}$
Correspondence: Antonio Ciudad Department of Clinical Research and Development, Eli Lilly \& Co, SA Avda de la Industria 30, 28108 Alcobendas, Madrid, Spain

Tel $+349 \quad 16233570$

Fax +349 I663 347I

Email ciudad_antonio@lilly.com 
In clinical practice, long-acting injectable formulations are a good option to improve treatment adherence, and thus improve the effectiveness of antipsychotic treatment, particularly in patients with a suboptimal response to previous oral treatments by ensuring delivery of the medication and simplifying administration..$^{5-7}$

Olanzapine long-acting injection (OLAI), the intramuscular depot formulation of olanzapine, is currently available for the treatment of patients with schizophrenia. The therapeutic efficacy of OLAI has been demonstrated in two pivotal Phase III randomized controlled trials. The short-term effectiveness of OLAI was established in an 8-week, placebocontrolled Phase III trial in adult patients $(\mathrm{n}=404)$ who were experiencing acute psychotic symptoms and met Diagnostic and Statistical Manual of Mental Disorders (DSM)-IV or DSM-IV-TR criteria for schizophrenia. ${ }^{8}$ In the other pivotal Phase III trial, the longer-term noninferiority of OLAI was demonstrated in adult patients with schizophrenia $(n=1,065)$ over a 24-week period (following randomization either to continue their current oral olanzapine dose or to switch to OLAI, after remaining stable for 4-8 weeks on open-label oral olanzapine). ${ }^{9}$ Additionally, in a third study (Phase IIIB), adult outpatients ( $\mathrm{n}=524$ ) with schizophrenia were randomized to receive OLAI $(n=264)$ or oral olanzapine $(n=260)$ for up to 2 years of open-label treatment. ${ }^{10,11}$ In the latter study, median times to all-cause discontinuation (primary outcome measure) did not differ significantly between the treatment groups..$^{10,11}$

This paper reports on a post hoc analysis from the 8-week pivotal Phase III randomized controlled trial in acute patients (hereafter referred to as the "short-term study") and from the 2-year randomized open-label Phase IIIB study in outpatients (hereafter referred to as the "long-term study") suffering from schizophrenia (according to DSM-IV criteria). The main objective of these post hoc analyses was to assess what clinical effects would be observed after switching from either oral olanzapine (OLZ) or from any other antipsychotic medication (non-OLZ) to OLAI.

\section{Materials and methods}

The two Phase III studies were selected for these post hoc analyses because they were the only studies with appropriate data available that allowed comparison between OLZpretreated and non-OLZ-pretreated patients who switched to OLAI. Both studies were conducted in compliance with the ethical principles laid down in the Declaration of Helsinki, good clinical practices, and applicable laws and regulations. For each investigational site, ethical review boards provided written approval of the study protocols and the patient informed consent documents.

\section{Source studies: main objectives and treatment groups}

Complete descriptions of the two trials, including details of study design and patient populations, have been previously reported, ${ }^{8,10,11}$ the methodologic details of each study are summarized in Figure 1.

The main objectives of the two source studies were to determine the efficacy and tolerability of OLAI relative to placebo (short-term study) or oral olanzapine (long-term study). Patients receiving oral olanzapine in combination with another antipsychotic medication before switching to OLAI and patients randomized to the placebo or oral olanzapine groups were not included in the present post hoc analyses (Figure 1).

\section{Post hoc analyses: main objective and treatment groups}

The main objective of these post hoc analyses was to assess what clinical effects would be observed after switching from either oral olanzapine (OLZ) or from any other antipsychotic medication (non-OLZ) to OLAI. For these analyses, two groups of patients were identified per source study based on their previous treatment before randomization to OLAI, ie, patients who switched from oral olanzapine monotherapy to OLAI and patients who switched from any other antipsychotic medication to OLAI (Figure 1).

\section{Post hoc measures}

Given that poor adherence to oral antipsychotic therapy is a major problem in the long-term management of schizophrenia, ${ }^{1}$ completion/discontinuation of treatment is recognized as a proxy measure of a medication's effectiveness in treating schizophrenia. ${ }^{12-14}$ Thus, time to all-cause discontinuation, rate of discontinuation, and reasons for discontinuation were used as proxy measures of effectiveness. Disease severity measures included mean change in Positive and Negative Syndrome Scale (PANSS) total, positive, and negative scores ${ }^{15}$ and mean change in Clinical Global Impression Severity (CGI-S) score. Safety/tolerability measures included incidence of treatment-emergent adverse events occurring in $\geq 5 \%$ and two or more patients; incidence of treatment-emergent serious adverse events occurring in two or more patients; categorical changes in metabolic parameters (ie, weight, fasting glucose, fasting triglycerides, total cholesterol, high-density lipoprotein cholesterol, and 


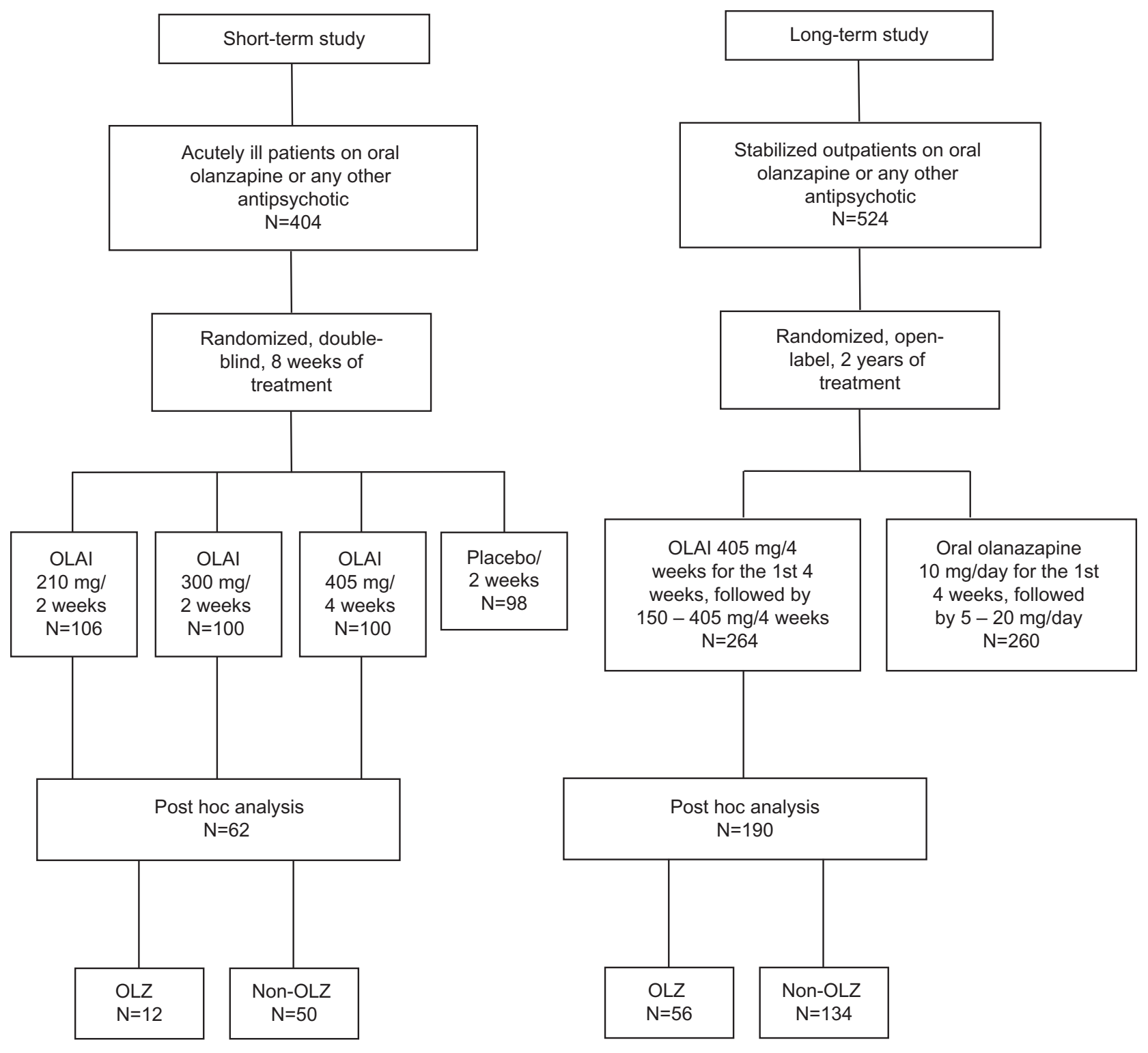

Figure I Patients' treatments before and during the original studies, and patient groups in the post hoc analyses. Only patients who had used OLZ or non-OLZ immediately before randomization to OLAI were included in the post hoc analyses.

Abbreviations: OLAI, olanzapine long-acting injection; OLZ, switched to OLAl from oral olanzapine monotherapy; non-OLZ, switched to OLAl from any other antipsychotic medication; $\mathrm{N}$, number of patients.

low-density lipoprotein cholesterol); incidence of treatmentemergent extrapyramidal symptoms (ie, dyskinesia, akathisia, and parkinsonism); and mean change in extrapyramidal symptom scores, assessed using the Abnormal Involuntary Movements Scale (for dyskinesia), ${ }^{16}$ Barnes Akathisia Scale,${ }^{17}$ and Simpson-Angus Scale (for parkinsonism). ${ }^{18}$

\section{Statistical analyses}

For the purpose of these post hoc analyses, the two patient groups (ie, patients who switched to OLAI from oral olanzapine monotherapy versus those who switched to OLAI from any other antipsychotic medication) were assessed using Kaplan-Meier tests, $t$-tests, and chi-square tests, as appropriate, without adjusting for any baseline variables, because the focus was to describe the outcomes of treatment with OLAI for both pretreatment groups. Mean changes from baseline (ie, start of OLAI treatment) to endpoint were analyzed using $t$-tests applying the last-observation-carried-forward (LOCF) approach. Statistical significance was defined as $P<0.05$ (two-sided), without adjustment for multiplicity, and should be viewed as indicative only. Data from both studies were statistically analyzed and are presented here separately. All post hoc statistical analyses were performed using SAS version 9.2 (SAS Institute Inc., Cary, NC, USA). 


\section{Results}

\section{Baseline characteristics}

As shown in Figure 1, data for 62 hospitalized patients with acute psychotic symptoms were included in the post hoc analyses from the short-term study ( 8 weeks of OLAI treatment); 12 of them switched to OLAI from oral olanzapine (hereafter referred to as the OLZ group) and 50 switched to OLAI from any other antipsychotic medication (hereafter referred to as the non-OLZ group). Separately from the shortterm study analyses, data for 190 stabilized outpatients from the long-term study ( 2 years of OLAI treatment) were also analyzed, ie, 56 in the OLZ and 134 in the non-OLZ patient groups (Figure 1). OLAI was given as $210 \mathrm{mg} / 2$ weeks, $300 \mathrm{mg} / 2$ weeks, or $405 \mathrm{mg} / 4$ weeks in the short-term study, and $150-405 \mathrm{mg} / 4$ weeks in the long-term study. The antipsychotic medications used by patients immediately before switching to OLAI are shown in Table 1.

Overall, patient demographics were similar at baseline between the OLZ and non-OLZ pretreatment groups in the short-term and long-term studies (Table 2). In each study group, most patients were male $(63 \%-75 \%)$ and Caucasian (42\%-68\%) or African-American (10\%-50\%), with mean ( \pm standard deviation) ages between $39 \pm 11.5$ years and $44 \pm 11.4$ years and a mean body mass index between $27.3 \pm 7.0 \mathrm{~kg} / \mathrm{m}^{2}$ and $29.2 \pm 5.8 \mathrm{~kg} / \mathrm{m}^{2}$. The only statistically significant difference in patient demographics was observed with body weight in the long-term study; patients in the OLZ group were heavier than in the non-OLZ group (mean $85.1 \pm 20.44 \mathrm{~kg}$ versus $78.2 \pm 21.61 \mathrm{~kg} ; P=0.039$ ).

Table I Antipsychotic medications used immediately before starting the olanzapine long-acting injection

\begin{tabular}{|c|c|c|c|c|}
\hline & \multicolumn{2}{|c|}{ Short-term study } & \multicolumn{2}{|c|}{ Long-term study } \\
\hline & $\begin{array}{l}\text { OLZ } \\
(N=12)\end{array}$ & $\begin{array}{l}\text { Non-OLZ } \\
(\mathrm{N}=50)\end{array}$ & $\begin{array}{l}\text { OLZ } \\
(\mathrm{N}=56)\end{array}$ & $\begin{array}{l}\text { Non-OLZ } \\
(\mathrm{N}=134)\end{array}$ \\
\hline Any previous & $12(100.0)$ & $50(100.0)$ & $56(100.0)$ & $134(100.0)$ \\
\hline \multicolumn{5}{|l|}{ APS, n (\%) } \\
\hline Risperidone & 0 & $20(40.0)$ & 0 & $45(33.6)$ \\
\hline Aripiprazole & 0 & $8(16.0)$ & 0 & $9(6.7)$ \\
\hline Depot APS & 0 & $15(30.0)$ & 0 & $4(3.0)$ \\
\hline Haloperidol & 0 & $4(8.0)$ & 0 & $24(17.9)$ \\
\hline Olanzapine & $12(100.0)$ & 0 & $56(100.0)$ & 0 \\
\hline Quetiapine & 0 & $2(4.0)$ & 0 & $17(12.7)$ \\
\hline Ziprasidone & 0 & I (2.0) & 0 & $12(9.0)$ \\
\hline Other typical APS & 0 & $5(10.0)$ & 0 & $35(26.1)$ \\
\hline Other atypical APS & 0 & 0 & 0 & $18(13.4)$ \\
\hline
\end{tabular}

Abbreviations: APS, antipsychotic medication; OLZ, switched to olanzapine longacting injection (OLAl) from oral olanzapine monotherapy; Non-OLZ, switched to OLAl from any other antipsychotic medication; N, number of patients who switched to OLAI treatment; $n$, number of patients who used any APS before switching to OLAl treatment.
As shown in Table 3, mean PANSS total scores were significantly different in the OLZ pretreatment groups compared with the non-OLZ groups in each study (shortterm, 95.0 versus 105.9; long-term, 51.7 versus 56.9 ). The mean baseline CGI-S scores were not significantly different between the pretreatment groups, but were numerically lower in the OLZ patients compared with non-OLZ patients in the short-term study (4.8 versus 4.9 , respectively) and in the long-term study (3.0 versus 3.3, respectively, see Table 3).

\section{Discontinuation rates}

As shown in Figure 2, the Kaplan-Meier survival analysis of time to all-cause discontinuation of OLAI treatment did not differ between OLZ patients and non-OLZ patients in the short-term study or long-term study. Similarly, as shown in Figure 3, OLAI discontinuation rates did not differ between OLZ patients and non-OLZ patients in the short-term study and long-term study at endpoints. As expected, OLAI discontinuation rates were generally lower in the short-term (8-week) study than in the long-term (2-year) study at endpoints (Figures 2 and 3). In addition, the reasons for discontinuation did not differ between the OLZ patients and non-OLZ patients in the short-term study or long-term study (Figure 3). The most common reasons for discontinuation of OLAI treatment were: lack of efficacy in the short-term study and clinical relapse in the long-term study, subject decision, adverse events in both studies, and, in the long-term study alone, lost to follow-up most probably due to the longer study design (Figure 3). In the long-term study, clinical relapse was defined as: hospitalization related to schizophrenia, or increase $\geq 25 \%$ from baseline in total PANSS score (if baseline score was $>40$ ) or an increase of 10 points (if baseline score was $\leq 40$ ), and at least a one-point increase from baseline score on the CGI-S, if the increase resulted in a CGI-S score $\geq 4$, deliberate self-injury or injury of others, or discontinuation from the study because of worsening psychosis. ${ }^{11}$

\section{Disease severity at study endpoints}

As shown in Table 4, at LOCF endpoints, no significant differences were detected in any disease severity measures (mean PANSS total, positive and negative, and CGI-S scores) between non-OLZ and OLZ pretreated patients in the short-term study or long-term study. However, numerical reductions in PANSS total and CGI-S scores were detected at endpoint (Table 4) relative to baseline (Table 3). Similarly, in the short-term study, no statistically significant differences were detected in mean change from baseline to LOCF 
Table 2 Baseline patient demographics

\begin{tabular}{|c|c|c|c|c|c|c|}
\hline & \multicolumn{3}{|c|}{ Short-term study } & \multicolumn{3}{|c|}{ Long-term study } \\
\hline & $\begin{array}{l}\text { OLZ } \\
(N=12)\end{array}$ & $\begin{array}{l}\text { Non-OLZ } \\
(\mathrm{N}=50)\end{array}$ & $P$-value & $\begin{array}{l}\text { OLZ } \\
(\mathrm{N}=56)\end{array}$ & $\begin{array}{l}\text { Non-OLZ } \\
(\mathrm{N}=134)\end{array}$ & $P$-value \\
\hline Age (years), mean (SD) & $39.2(11.5)$ & 43.7 (II.4) & 0.233 & $40.7(12.6)$ & $42.2(10.5)$ & 0.437 \\
\hline Male, \% & $9(75.0)$ & $35(70.0)$ & 0.732 & 40 (7I.4) & $84(62.7)$ & 0.249 \\
\hline Ethnicity, \% & & & 0.085 & & & 0.123 \\
\hline Caucasian & $5(4 I .7)$ & $34(68.0)$ & & $29(51.8)$ & $91(67.9)$ & \\
\hline African & $6(50.0)$ & $15(30.0)$ & & $7(12.5)$ & $13(9.7)$ & \\
\hline Hispanic & I (8.3) & 0 & & $8(14.3)$ & II (8.2) & \\
\hline Native American & 0 & 0 & & $2(3.6)$ & 0 & \\
\hline East Asian & 0 & I (2.0) & & $8(14.3)$ & $14(10.4)$ & \\
\hline West Asian & 0 & 0 & & $2(3.6)$ & $5(3.7)$ & \\
\hline BMI $\left(\mathrm{kg} / \mathrm{m}^{2}\right)$, mean $(\mathrm{SD})$ & $29.1(5.9)$ & $28.5(6.7)$ & 0.769 & $29.2(5.8)$ & $27.3(7.0)$ & 0.058 \\
\hline Weight (kg), mean (SD) & $84.7(16.8)$ & $85.6(24.3)$ & 0.872 & $85.1(20.4)$ & $78.2(21.6)$ & 0.039 \\
\hline
\end{tabular}

endpoint PANSS and CGI-S scores in the OLZ and non-OLZ groups. In the long-term study, statistically significant differences in reductions of the mean change from baseline of PANSS total and negative scores were detected in non-OLZ patients, relative to OLZ patients.

\section{Safety and tolerability assessments}

There were no statistically significant differences in the proportions of patients experiencing any treatment-emergent adverse event between the OLZ group and non-OLZ groups in the short-term study $(91.7 \%$ versus $72.0 \%$, respectively) or long-term study (66.1\% versus $69.4 \%$, respectively). Treatment-emergent adverse events in $\geq 5 \%$ and two or more OLZ or non-OLZ patients in either of the studies included diarrhea, increased weight, somnolence, and insomnia (see Table 5).

In the short-term study, no statistically significant difference in the proportion of patients who experienced a treatmentemergent serious adverse event was found between OLZ and non-OLZ pretreatment groups. In the long-term study, a significantly higher proportion of patients in the OLZ pretreatment group than in the non-OLZ pretreatment group (19.6\% versus $5.2 \%$, respectively) experienced a treatment-emergent serious adverse event. The main serious treatment-emergent adverse events recorded in either/both studies were schizophrenia, anxiety, and psychotic disorder (Table 6).

Potentially clinically significant changes in metabolic parameters from baseline to endpoint were defined as any such changes that were larger than in a set of predefined values. The predefined values were: weight gain, $\geq 7 \%$ increase from baseline; fasting glucose, $\geq 7 \mathrm{mmol} / \mathrm{L}$ following baseline of $<5.56 \mathrm{mmol} / \mathrm{L}$; fasting triglycerides, $\geq 2.26 \mathrm{mmol} / \mathrm{L}$ following baseline of $<1.69 \mathrm{mmol} / \mathrm{L}$; total fasting cholesterol, $\geq 6.21 \mathrm{mmol} / \mathrm{L}$ following baseline of $<5.17 \mathrm{mmol} / \mathrm{L}$; fasting low-density lipoprotein cholesterol, $\geq 4.13 \mathrm{mmol} / \mathrm{L}$ following baseline $<2.58 \mathrm{mmol} / \mathrm{L}$; and fasting high-density lipoprotein cholesterol, $<1.03 \mathrm{mmol} / \mathrm{L}$ following baseline of $\geq 1.03 \mathrm{mmol} / \mathrm{L}$. These changes were assessed in patients in both the short-term and long-term studies (see Figure 4). Of these parameters, only increase in body weight from baseline in the short-term study was statistically significant, with a greater proportion of patients in the OLZ pretreatment group $(58.3 \%)$ experiencing weight increases than in the non-OLZ pretreatment group $(26.0 \%)$.

Table 3 Baseline disease characteristics

\begin{tabular}{|c|c|c|c|c|c|c|}
\hline & \multicolumn{3}{|c|}{ Short-term study } & \multicolumn{3}{|c|}{ Long-term study } \\
\hline & $\begin{array}{l}\text { OLZ } \\
(N=12)\end{array}$ & $\begin{array}{l}\text { Non-OLZ } \\
(\mathrm{N}=50)\end{array}$ & $P$-value & $\begin{array}{l}\text { OLZ } \\
(\mathrm{N}=56)\end{array}$ & $\begin{array}{l}\text { Non-OLZ } \\
(\mathrm{N}=134)\end{array}$ & $P$-value \\
\hline Episodes in previous 24 months, mean (SD) & $5.3(3.2)$ & $3.1(3.0)$ & 0.056 & $2.8(2.2)$ & $2.6(1.3)$ & 0.448 \\
\hline Length of current episode (months), mean (SD) & $1.9(1.9)$ & $3.3(6.2)$ & 0.181 & $7.2(4.6)$ & $5.3(5.0)$ & 0.011 \\
\hline PANSS total score, mean (SD) & $95.0(10.3)$ & $105.9(18.1)$ & 0.009 & $51.7(10.8)$ & $56.9(9.5)$ & 0.003 \\
\hline CGI-S score, mean (SD) & $4.8(0.6)$ & $4.9(0.8)$ & 0.540 & $3.0(1.0)$ & $3.3(0.7)$ & 0.062 \\
\hline
\end{tabular}

Abbreviations: CGI-S, Clinical Global Impression Severity; OLZ, switched to olanzapine long-acting injection (OLAI) from oral olanzapine monotherapy; Non-OLZ, switched to OLAl from any other antipsychotic medication; PANSS, Positive and Negative Syndrome Scale; N, number of patients who switched to OLAl treatment; SD, standard deviation. 


\section{Short-term study}

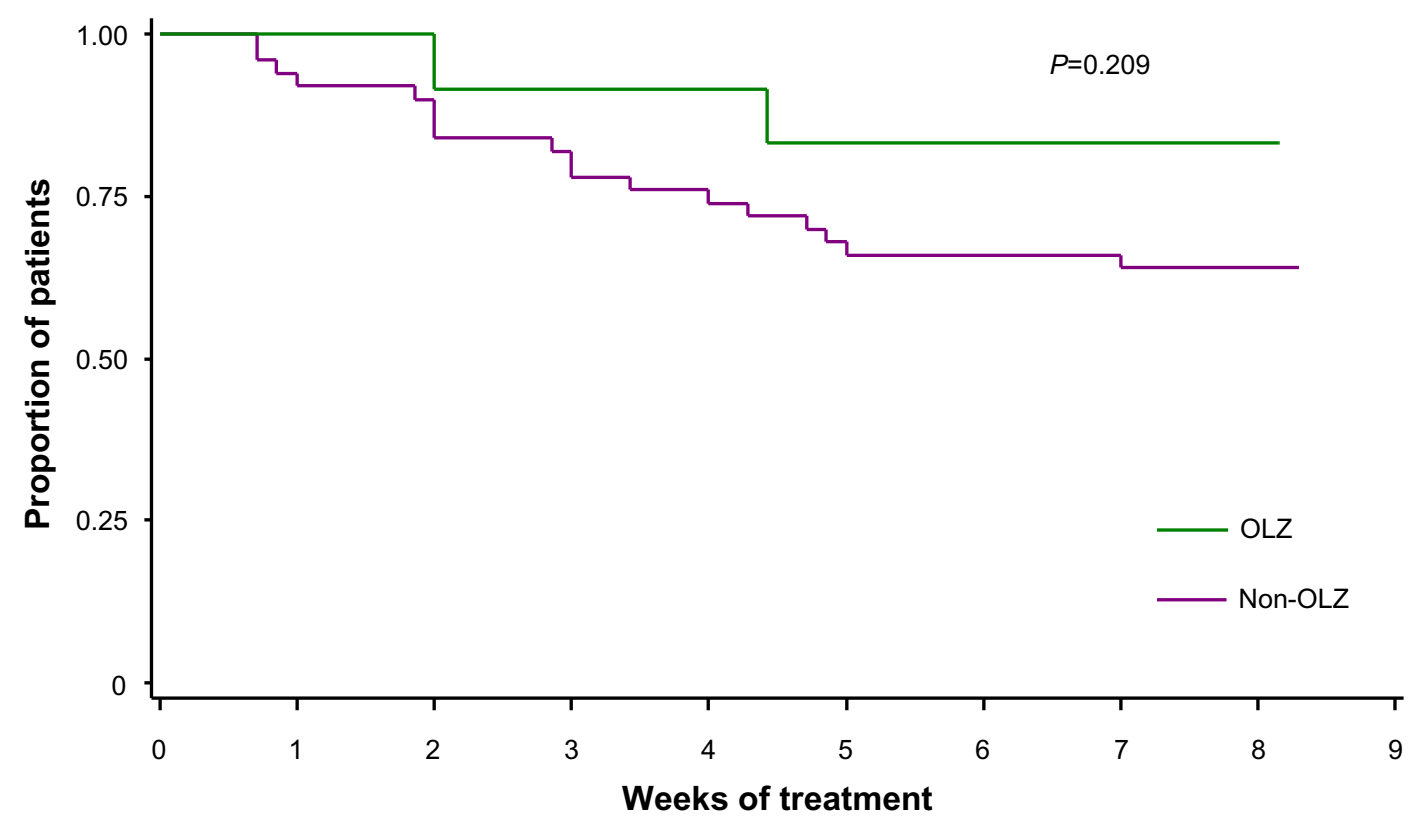

\section{Long-term study}

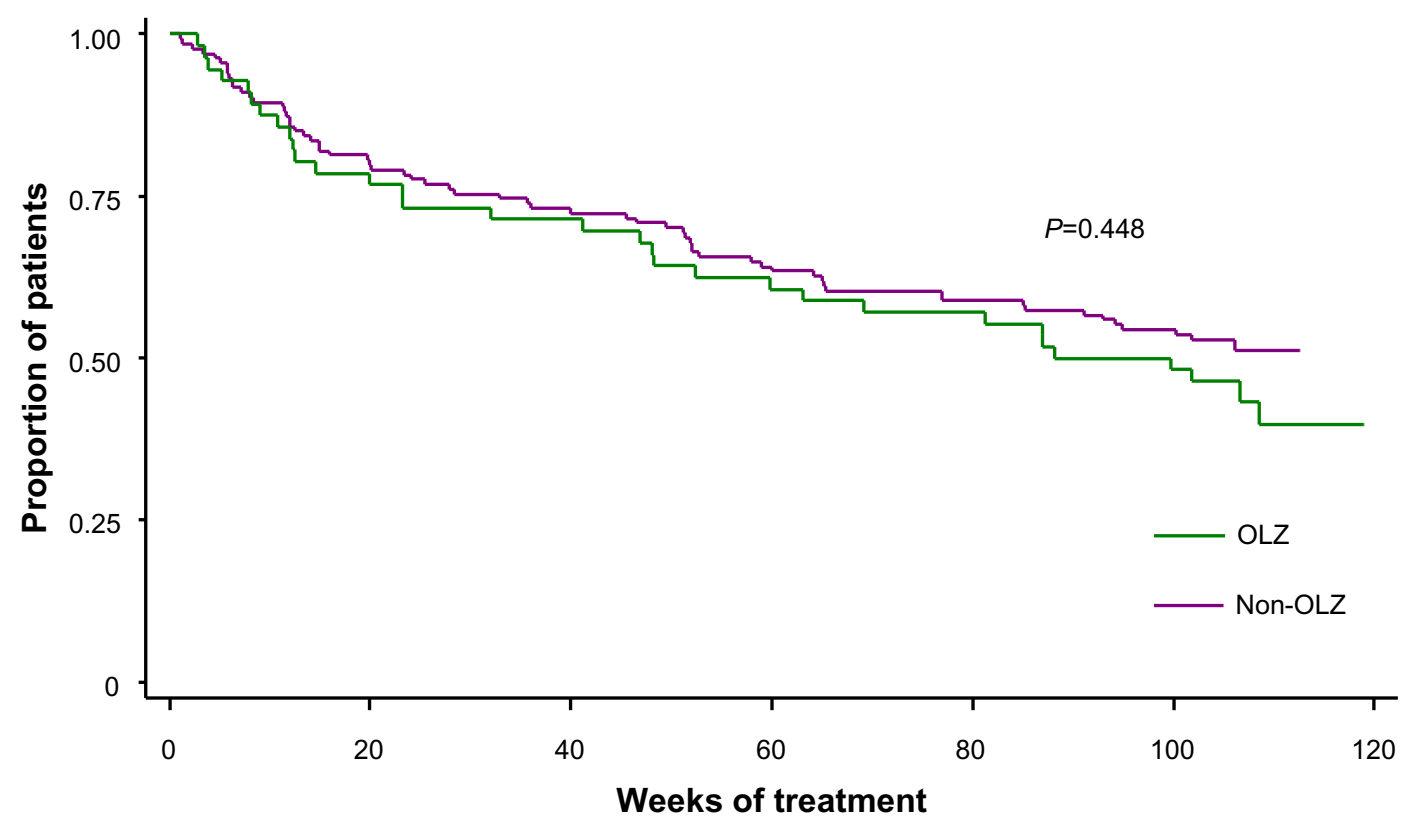

Figure 2 Kaplan-Meier survival analysis of time to all-cause discontinuation from OLAl treatment. No statistically significant differences were detected in times to all-cause discontinuation in the short-term study or in the long-term study.

Abbreviations: OLAl, olanzapine long-acting injection; OLZ, switched to OLAl from oral olanzapine monotherapy; non-OLZ, switched to OLAl from any other antipsychotic medication.

After identifying potentially clinically significant changes in metabolic parameters, the investigators decided whether these changes were clinically significant, and if so, these changes were classified as adverse events. Metabolic changes based on adverse event reporting, rather than solely based on laboratory or clinical measurements, are shown in Table 5.

\section{Extrapyramidal symptoms}

In the short-term and long-term studies, some potentially clinically significant differences were detected in extrapyramidal symptoms, which occurred at any time after switching to OLAI treatment. Specifically, potentially clinically significant changes that were 


\section{Short-term study}

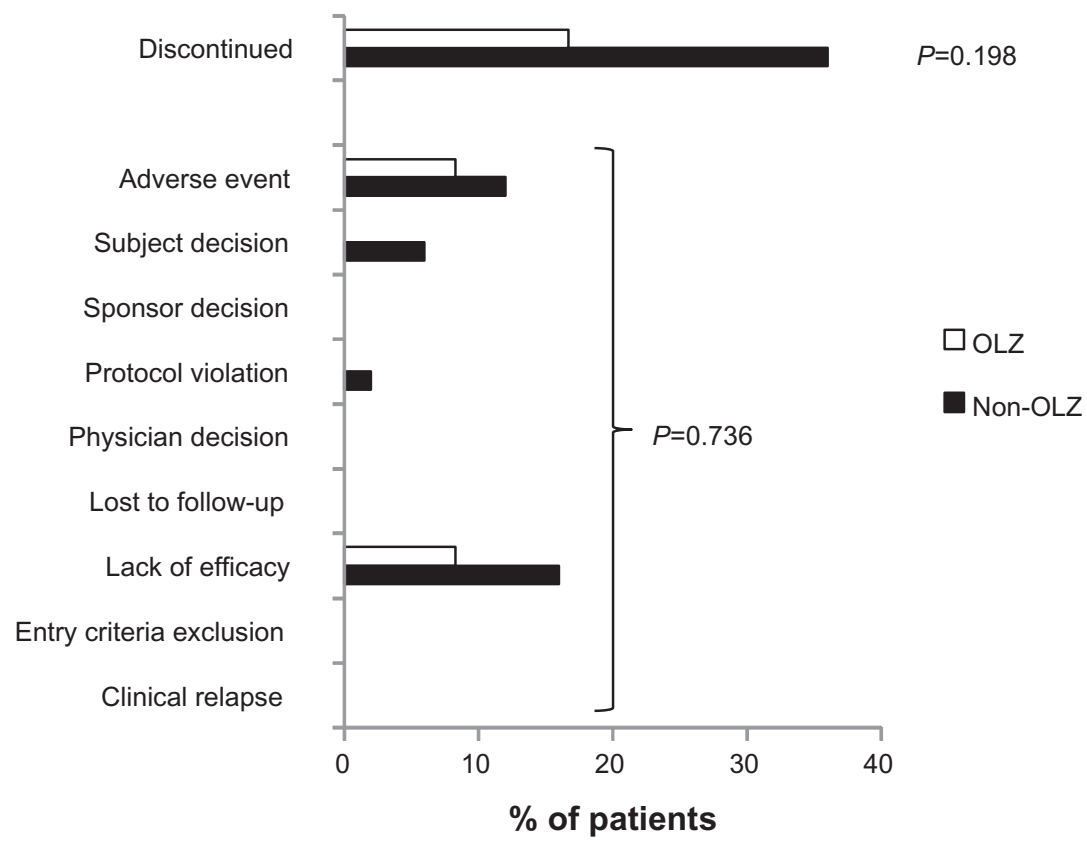

\section{Long-term study}

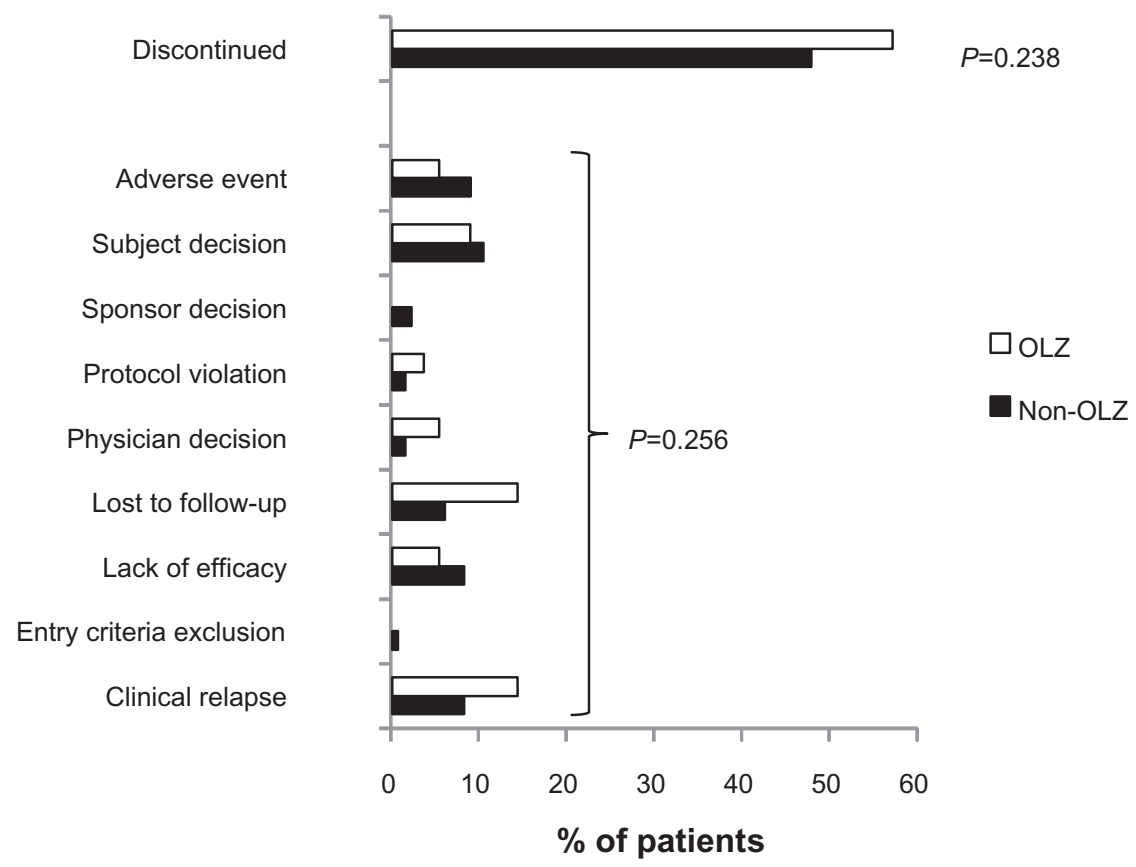

Figure 3 Rates of discontinuation and reasons for discontinuation from OLAl treatment. No statistically significant differences were detected in discontinuation rates in the short-term study or in the long-term study.

Abbreviations: OLAI, olanzapine long-acting injection; OLZ, switched to OLAl from oral olanzapine monotherapy; non-OLZ, switched to OLAl from any other antipsychotic medication.

significantly more frequent in OLZ patients than non-OLZ patients were: akathisia in the short-term study $(33.3 \%$ versus $10.0 \%$ ) and long-term study (8.9\% versus $1.5 \%$ ); and parkinsonism in the long-term study $(8.9 \%$ versus $2.2 \%$, Figure 5).
In the short-term study, mean extrapyramidal symptom scores (for dyskinesia, akathisia, and parkinsonism) decreased from baseline to endpoints in OLZ and nonOLZ groups, with the exception of a mean 0.9 increase in Simpson-Angus total score (for parkinsonism) in the OLZ 
Table 4 Disease severity measures after treatment with olanzapine long-acting injection

\begin{tabular}{|c|c|c|c|c|c|c|}
\hline & \multicolumn{3}{|c|}{ Short-term study } & \multicolumn{3}{|c|}{ Long-term study } \\
\hline & $\begin{array}{l}\text { OLZ } \\
(N=12 ; n=10)\end{array}$ & $\begin{array}{l}\text { Non-OLZ } \\
(N=50 ; n=32)\end{array}$ & $P$-value & $\begin{array}{l}\text { OLZ } \\
(N=56 ; n=24)\end{array}$ & $\begin{array}{l}\text { Non-OLZ } \\
(\mathrm{N}=134 ; \mathrm{n}=70)\end{array}$ & $P$-value \\
\hline \multicolumn{7}{|c|}{ LOCF endpoint in disease severity measures } \\
\hline PANSS total score, mean (SD) & $79.4(13.7)$ & $73.3(19.7)$ & 0.288 & $48.0(10.9)$ & $45.1(11.6)$ & 0.280 \\
\hline PANSS positive, mean (SD) & $19.6(6.2)$ & $16.3(6.4)$ & 0.170 & $9.9(2.7)$ & $9.3(2.9)$ & 0.347 \\
\hline PANSS negative, mean (SD) & $20.2(3.2)$ & $19.6(5.7)$ & 0.672 & I5.0 (5.3) & $13.3(4.3)$ & 0.166 \\
\hline \multirow[t]{2}{*}{ CGI-S, mean (SD) } & $4.1(0.7)$ & $3.6(0.8)$ & 0.066 & $2.6(0.9)$ & $2.5(0.8)$ & 0.412 \\
\hline & $\begin{array}{l}\text { OLZ } \\
(N=\mid 2 ; n=12)\end{array}$ & $\begin{array}{l}\text { Non-OLZ } \\
(\mathrm{N}=50 ; n=50)\end{array}$ & $P$-value & $\begin{array}{l}\text { OLZ } \\
(N=56 ; n=47)\end{array}$ & $\begin{array}{l}\text { Non-OLZ } \\
(N=134 ; n=126)\end{array}$ & $P$-value \\
\hline \multicolumn{7}{|c|}{ Mean change from baseline to LOCF endpoint in disease severity measures } \\
\hline PANSS total (SD) & $-13.4(13.4)$ & $-20.8(25.0)$ & 0.166 & $3.9(15.9)$ & $-3.6(16.4)$ & 0.008 \\
\hline PANSS positive (SD) & $-4.3(4.5)$ & $-6.6(7.5)$ & 0.175 & $0.7(5.0)$ & $-0.9(4.5)$ & 0.061 \\
\hline PANSS negative (SD) & $-1.8(3.5)$ & $-4.5(6.0)$ & 0.054 & $1.2(4.4)$ & $-1.6(4.7)$ & $<0.001$ \\
\hline CGI-S (SD) & $-0.4(\mathrm{I} . \mathrm{I})$ & $-0.7(1.1)$ & 0.367 & $-0.1(0.8)$ & $-0.3(1.0)$ & 0.112 \\
\hline
\end{tabular}

Abbreviations: CGI-S, Clinical Global Impression Severity; LOCF, last-observation-carried-forward; OLZ, switched to olanzapine long-acting injection (OLAI) from oral olanzapine monotherapy; non-OLZ, switched to OLAI from any other antipsychotic medication; N, number of patients who switched to OLAl treatment; n, number of patients at the LOCF endpoint; PANSS, Positive and Negative Syndrome Scale; SD, standard deviation.

group (Figure 6). However, no extrapyramidal symptom scores differed significantly in non-OLZ patients versus OLZ patients in the short-term study. In the long-term study, mean extrapyramidal symptom scores decreased from baseline in the non-OLZ group, but there was no clinically significant difference in OLZ patients. Thus, mean Barnes scores for akathisia were significantly lower for non-OLZ patients than for OLZ patients ( -0.6 versus 0.0$)$, although extrapyramidal symptom scores did not differ significantly between the pretreatment groups for parkinsonism or dyskinesia in the long-term study.

\section{Discussion}

These post hoc analyses suggest that patients suffering from schizophrenia and switching from non-OLZ to OLAI did not experience lower tolerability or less effectiveness compared

Table 5 Treatment-emergent adverse events occurring in $>5.0 \%$ and two or more patients

\begin{tabular}{|c|c|c|c|c|c|c|}
\hline & \multicolumn{3}{|c|}{ Short-term study } & \multicolumn{3}{|c|}{ Long-term study } \\
\hline & $\begin{array}{l}\mathrm{OLZ} \\
(\mathrm{N}=12)\end{array}$ & $\begin{array}{l}\text { Non-OLZ } \\
(\mathrm{N}=50)\end{array}$ & $P$-value & $\begin{array}{l}\text { OLZ } \\
(N=56)\end{array}$ & $\begin{array}{l}\text { Non-OLZ } \\
(\mathrm{N}=134)\end{array}$ & $P$-value \\
\hline $\begin{array}{l}\text { Any treatment-emergent adverse } \\
\text { events, } \mathrm{n}(\%)\end{array}$ & II (9I.7) & $36(72.0)$ & 0.153 & $37(66.1)$ & $93(69.4)$ & 0.652 \\
\hline Diarrhea & 0 & $2(4.0)$ & & $3(5.4)$ & $5(3.7)$ & \\
\hline Dyspepsia & 0 & $3(6.0)$ & & 0 & $\mathrm{I}(0.7)$ & \\
\hline Nasopharyngitis & $\mathrm{I}(8.3)$ & $2(4.0)$ & & $4(7.1)$ & $7(5.2)$ & \\
\hline Upper respiratory tract infection & I (8.3) & I (2.0) & & $3(5.4)$ & $3(2.2)$ & \\
\hline Weight decreased & 0 & 0 & & $\mathrm{I}(\mathrm{I} .8)$ & II (8.2) & \\
\hline Weight increased & 0 & $2(4.0)$ & & $7(12.5)$ & $24(17.9)$ & \\
\hline Hyperlipidemia & $2(16.7)$ & 0 & & 0 & 0 & \\
\hline Increased appetite & 0 & 0 & & $\mathrm{I}(\mathrm{l} .8)$ & $8(6.0)$ & \\
\hline Headache & $4(33.3)$ & $10(20.0)$ & & $3(5.4)$ & $7(5.2)$ & \\
\hline Lethargy & $2(16.7)$ & 0 & & $\mathrm{I}(\mathrm{I} .8)$ & $\mathrm{I}(0.7)$ & \\
\hline Sedation & I (8.3) & $4(8.0)$ & & $2(3.6)$ & $2(1.5)$ & \\
\hline Somnolence & 0 & I (2.0) & & $5(8.9)$ & $14(10.4)$ & \\
\hline Agitation & $2(16.7)$ & $5(10.0)$ & & $2(3.6)$ & $3(2.2)$ & \\
\hline Anxiety & $3(25.0)$ & I (2.0) & & $8(14.3)$ & $12(9.0)$ & \\
\hline Insomnia & $2(16.7)$ & $7(14.0)$ & & $6(10.7)$ & $17(12.7)$ & \\
\hline Schizophrenia & 0 & 0 & & $5(8.9)$ & $2(1.5)$ & \\
\hline Cough & $2(16.7)$ & 0 & & 0 & I (0.7) & \\
\hline Pharyngolaryngeal pain & $3(25.0)$ & I (2.0) & & 0 & 0 & \\
\hline
\end{tabular}

Abbreviations: OLZ, switched to olanzapine long-acting injection (OLAl) from oral olanzapine monotherapy; non-OLZ, switched to OLAl from any other antipsychotic medication; $\mathrm{N}$, number of patients who switched to OLAl treatment; $n$, number of patients who experienced at least one treatment-emergent adverse event. 
Table 6 Treatment-emergent serious adverse events occurring in two or more patients

\begin{tabular}{|c|c|c|c|c|c|c|}
\hline & \multicolumn{3}{|c|}{ Short-term study } & \multicolumn{3}{|c|}{ Long-term study } \\
\hline & $\begin{array}{l}\text { OLZ } \\
(N=12)\end{array}$ & $\begin{array}{l}\text { Non-OLZ } \\
(\mathrm{N}=50)\end{array}$ & $P$-value & $\begin{array}{l}\text { OLZ } \\
(N=56)\end{array}$ & $\begin{array}{l}\text { Non-OLZ } \\
(\mathrm{N}=134)\end{array}$ & $P$-value \\
\hline $\begin{array}{l}\text { Any treatment-emergent serious } \\
\text { adverse events, } n(\%)\end{array}$ & $3(25.0)$ & $4(8.0)$ & 0.095 & II (19.6) & $7(5.2)$ & 0.002 \\
\hline Any psychiatric disorder & $2(16.7)$ & I (2.0) & & $8(14.3)$ & $6(4.5)$ & \\
\hline Anxiety & I (8.3) & 0 & & $2(3.6)$ & 0 & \\
\hline Psychotic disorder & 0 & I (2.0) & & $\mathrm{I}(\mathrm{I} .8)$ & $3(2.2)$ & \\
\hline Schizophrenia & 0 & 0 & & $5(8.9)$ & $2(1.5)$ & \\
\hline
\end{tabular}

Abbreviations: OLZ, switched to olanzapine long-acting injection (OLAI) from oral olanzapine monotherapy; non-OLZ, switched to OLAl from any other antipsychotic medication; N, number of patients who switched to OLAl treatment; $n$, number patients of who experienced at least one treatment-emergent serious adverse event.

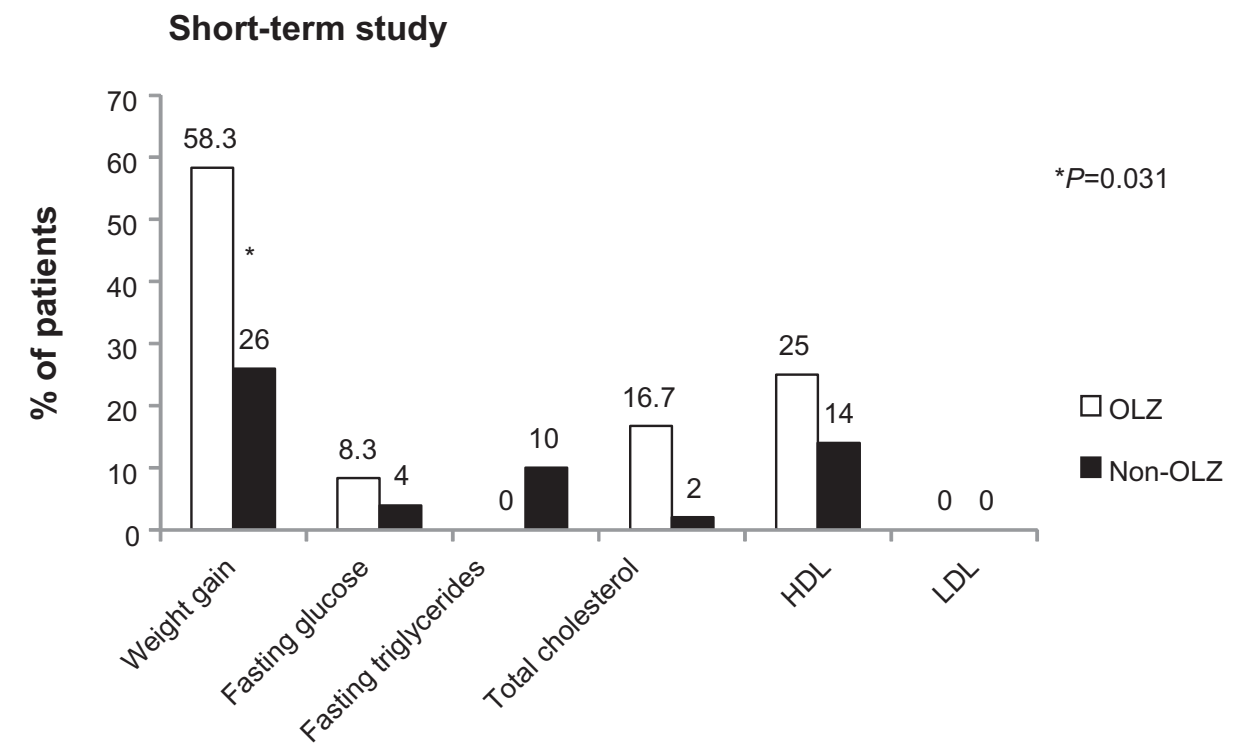

\section{Long-term study}

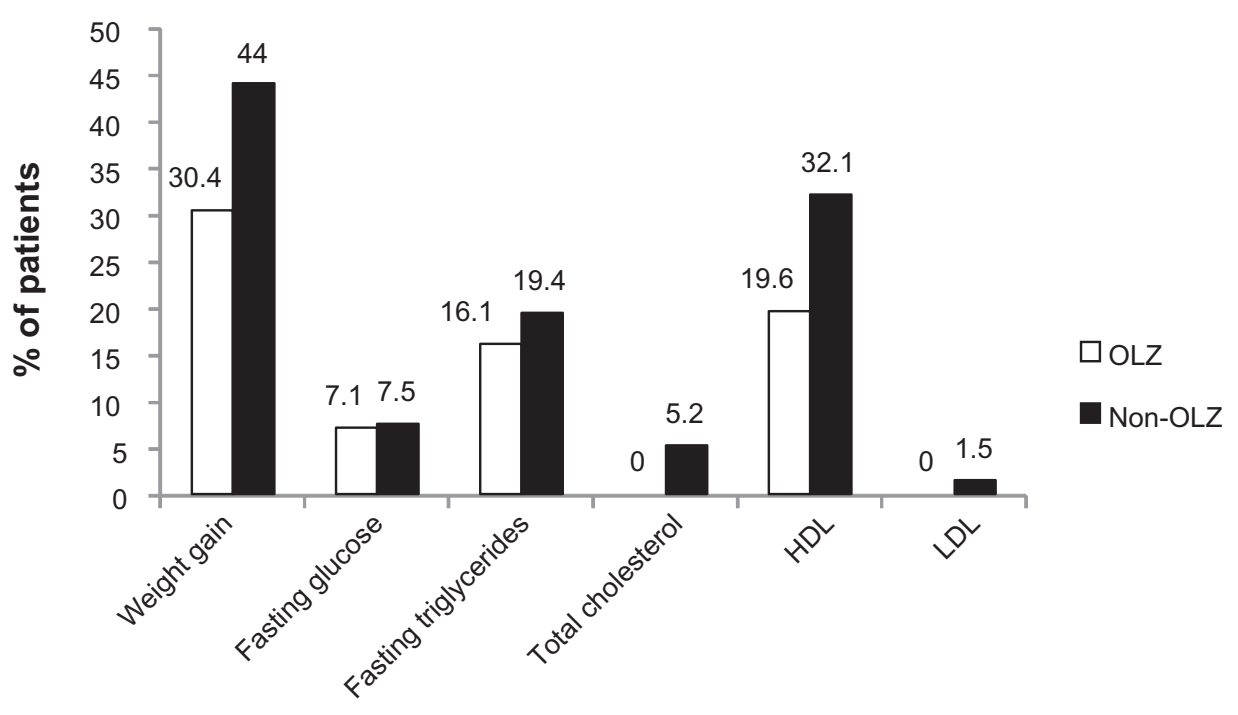

Figure 4 Potentially clinically significant changes in metabolic parameters after switching to OLAl treatment. The only statistically significant difference detected in potentially clinically significant changes was "weight gain" in the short-term study. Definitions: weight gain, $\geq 7 \%$ increase from baseline; fasting glucose, $\geq 7 \mathrm{mmol} / \mathrm{L}$ following baseline of $<5.56 \mathrm{mmol} / \mathrm{L}$; fasting triglycerides, $\geq 2.26 \mathrm{mmol} / \mathrm{L}$ following baseline of $<1.69 \mathrm{mmol} / \mathrm{L}$; total fasting cholesterol, $\geq 6.21 \mathrm{mmol} / \mathrm{L}$ following baseline of $<5.17 \mathrm{mmol} / \mathrm{L}$; fasting $\mathrm{LDL}, \geq 4.13 \mathrm{mmol} / \mathrm{L}$ following baseline $<2.58 \mathrm{mmol} / \mathrm{L}$; fasting $\mathrm{HDL},<1.03 \mathrm{mmol} / \mathrm{L}$ following baseline of $\geq 1.03 \mathrm{mmol} / \mathrm{L}$.

Abbreviations: HDL, high-density lipoprotein; LDL, low-density lipoprotein; OLAl, olanzapine long-acting injection; OLZ, switched to OLAI from oral olanzapine monotherapy; non-OLZ, switched to OLAl from any other antipsychotic medication. 


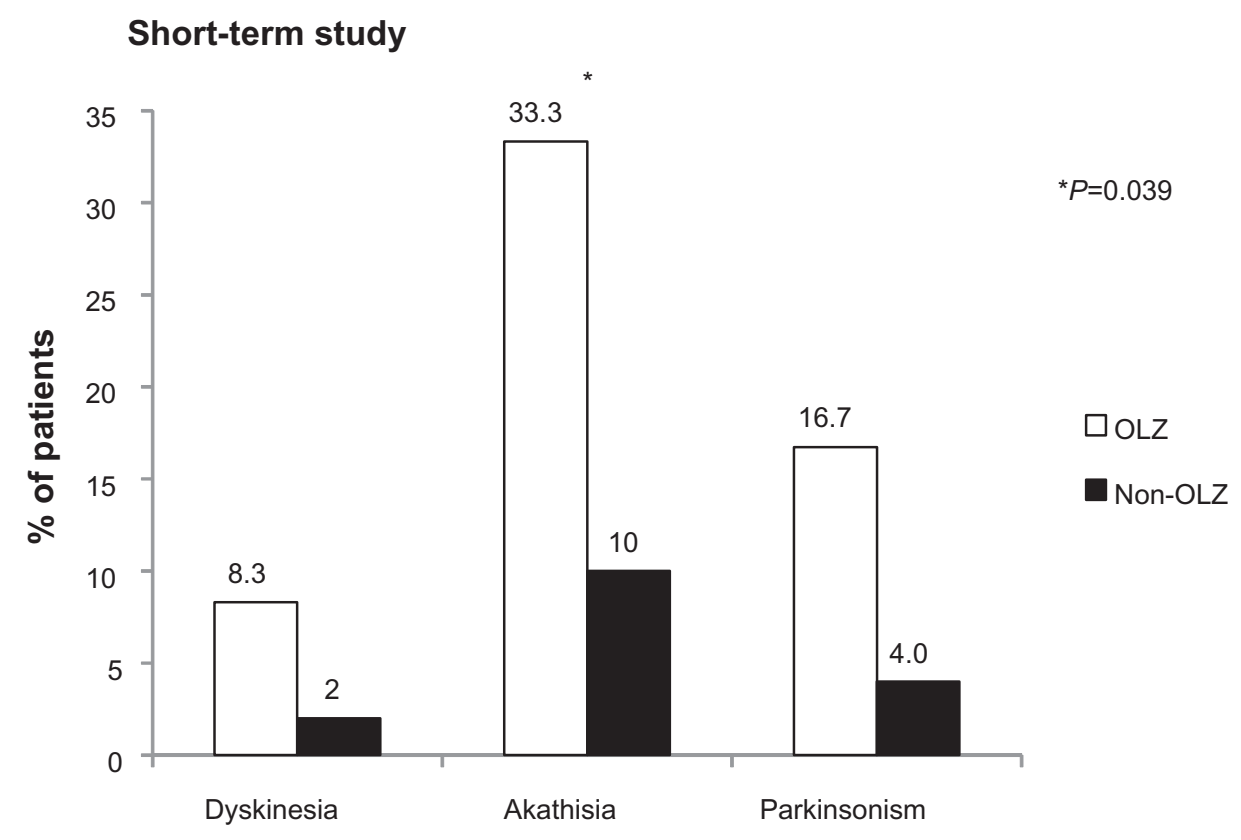

\section{Long-term study}

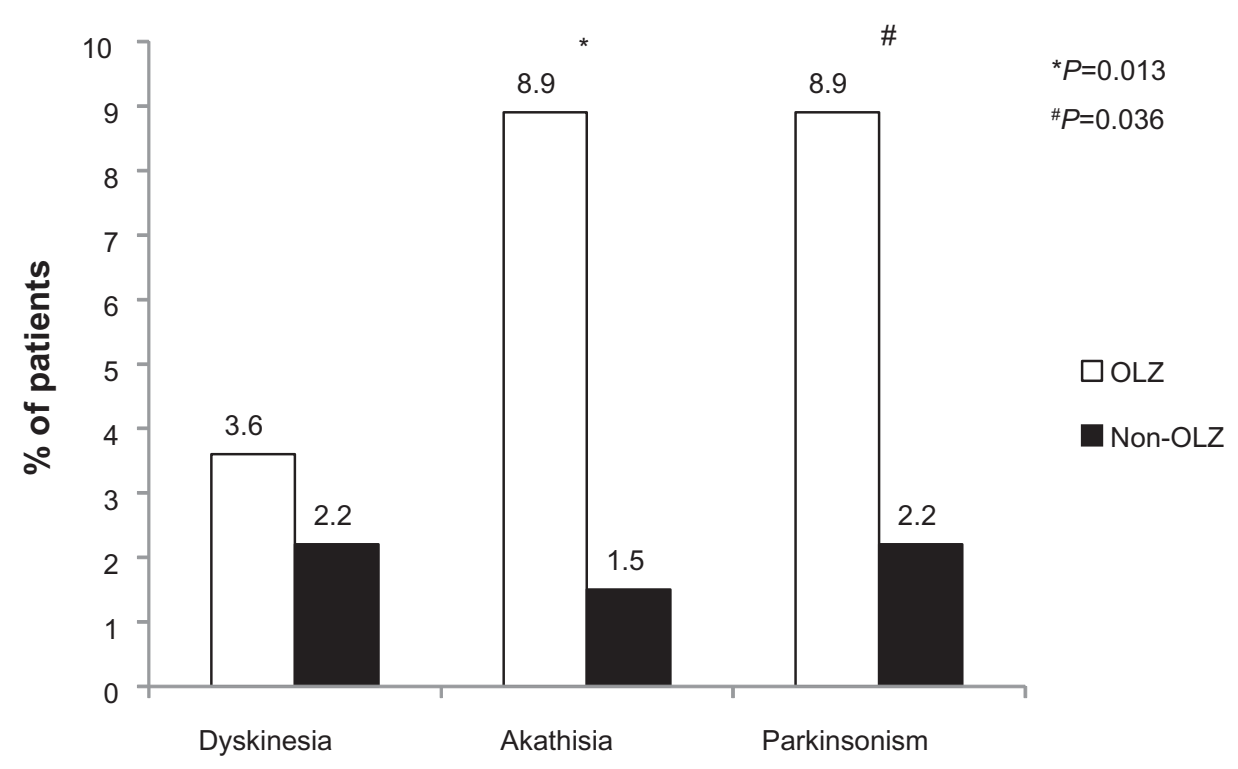

Figure 5 Potentially clinically significant changes in extrapyramidal symptoms at any time after switching to OLAl treatment. Statistically significant differences were detected in akathisia (in the short-term and long-term studies) and parkinsonism (in the long-term study).

Abbreviations: OLAl, olanzapine long-acting injection; OLZ, switched to OLAI from oral olanzapine monotherapy; non-OLZ, switched to OLAl from any other antipsychotic medication.

with patients switching from oral OLZ to OLAI in either short-term (8-week) or long-term (2-year) studies. However, these findings should be interpreted with care, particularly due to the small sample size (eg, only 12 patients in the OLZ group from the short-term study) and differences in patients' clinical profiles.

Given that poor adherence to oral antipsychotic therapy is a major problem in the long-term management of schizophrenia, ${ }^{1}$ completion/discontinuation of treatment is recognized as a proxy measure of a medication's effectiveness in treating schizophrenia. ${ }^{12-14}$ In addition, measuring discontinuation is said to integrate "patients' and clinicians' judgments of efficacy, safety, and tolerability into a global measure of effectiveness that reflects their evaluation of therapeutic benefits in relation to undesirable effects". ${ }^{12}$ 


\section{Short-term study}

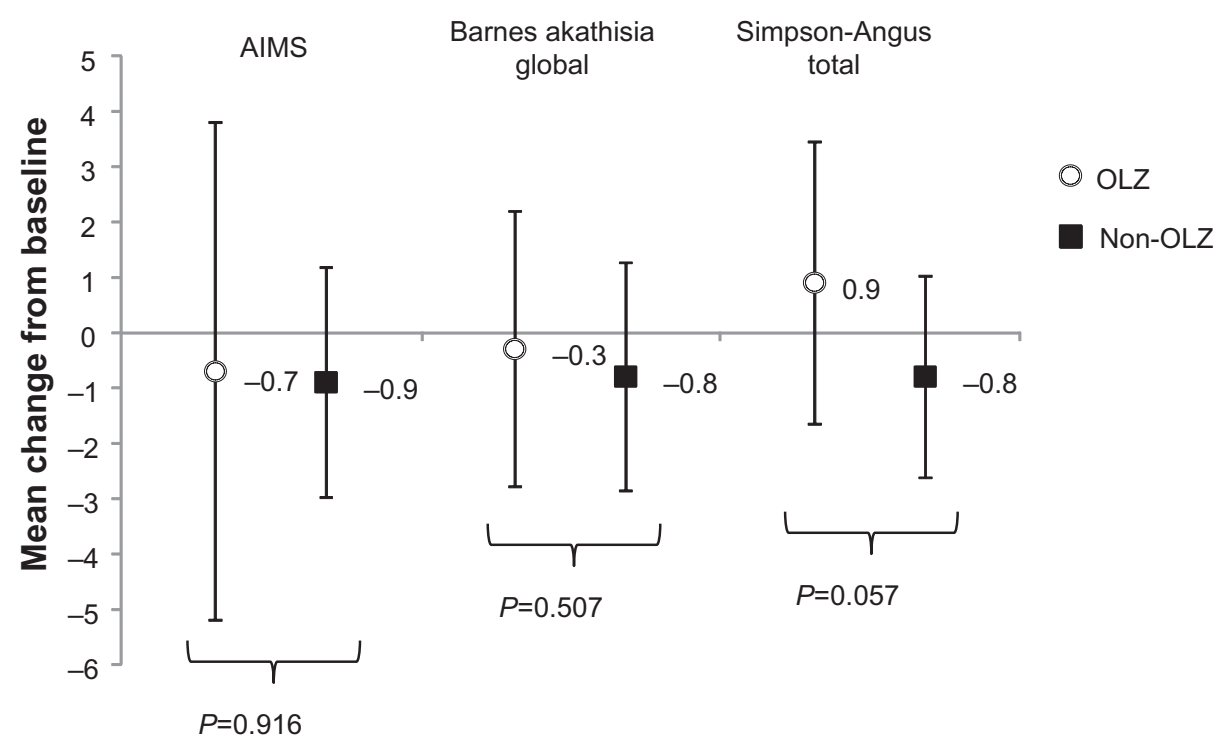

\section{Long-term study}

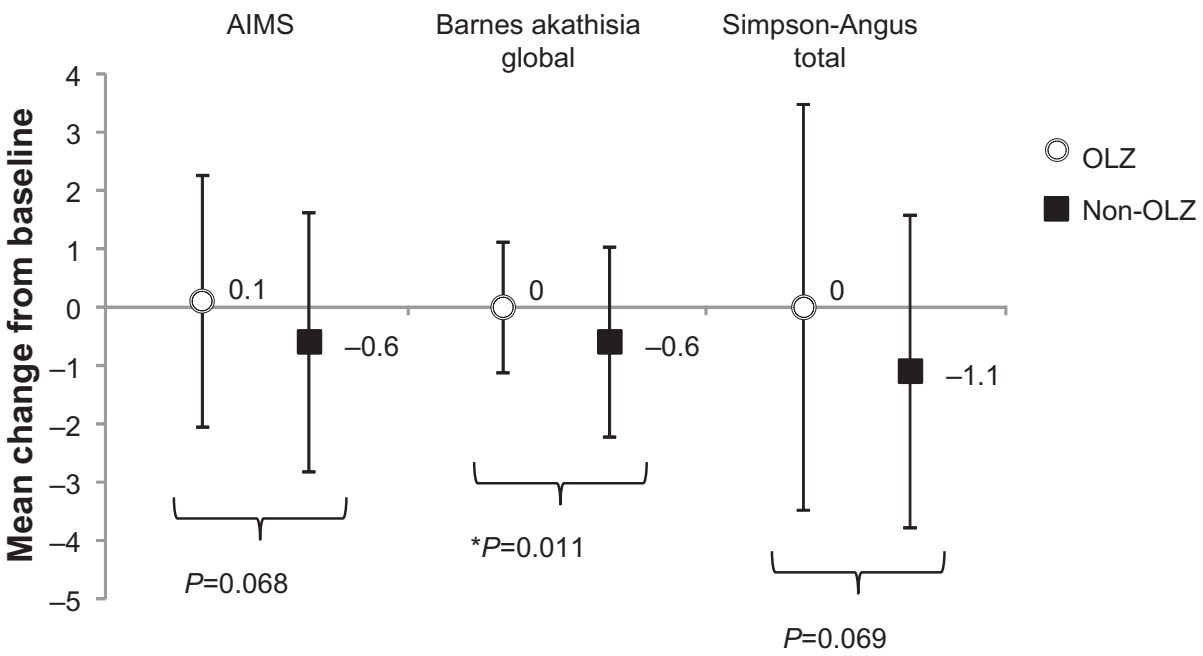

Figure 6 Mean (SD) changes in extra pyramidal symptom scores. The only statistically significant difference was detected in the Barnes Akathisia Rating Scale in the longterm study.

Abbreviations: OLAl, olanzapine long-acting injection; OLZ, switched to OLAl from oral olanzapine monotherapy; non-OLZ, switched to OLAI from any other antipsychotic medication; SD, standard deviation; AIMS, Abnormal Involuntary Movement Scale.

In our analysis, time to all-cause discontinuation, percentages of patients who discontinued OLAI treatment, and reasons for discontinuation (eg, lack of efficacy, adverse events) were similar for OLZ patients and non-OLZ patients. Hence, the effectiveness of OLAI (as shown by treatment discontinuation) did not appear to be affected by the type of antipsychotic treatment that patients switched from. These findings are compatible with those from several other studies ${ }^{12,13,19,20}$ that suggest the effectiveness of olanzapine (shown by treatment discontinuation) is equal to and often greater than the effectiveness of a range of other typical and atypical antipsychotics.

In the current analyses, we also measured disease severity using PANSS and CGI-S scores. Mean PANSS total scores were different at baseline (non-OLZ patients had symptoms that were more severe than those of OLZ patients) in both the 
short-term and long-term studies, while baseline mean CGI-S scores did not differ significantly between pretreatment groups. However there were no statistically significant differences in mean PANSS total scores, or between mean CGI-S scores, at the end of the 8-week or 2-year follow-up periods. Thus, non-OLZ patients may have noninferior or even greater clinical benefit (ie, potentially with better control of psychotic symptoms) after starting treatment with OLAI than OLZ patients. Moreover, in the 2-year study, mean changes from baseline to endpoint in PANSS total and in PANSS negative scores confirmed that these patients may have experienced noninferior or greater clinical benefit than oral OLZ patients by starting treatment with OLAI. Regarding the differences in baseline PANSS between the non-OLZ and OLZ groups, these may have been due to the fact that our post hoc analyses were based on nonrandomized comparisons.

While it should be reiterated that these analyses were complicated by non-OLZ patients having a higher mean PANSS total score (and thus more severe symptoms) at baseline than OLZ patients, these data may indicate that the non-OLZ group had more room for improvement in symptom control. Moreover, this is not an unexpected result, because the non-OLZ treatments may not have been as effective as oral OLZ before switching to OLAI. This suggestion is based on the clinical improvements (by means of PANSS scores) of olanzapine being greater than those of various other typical and atypical antipsychotics in two large meta-analyses, ${ }^{21,22}$ as well as the aforementioned similar or greater effectiveness (discontinuation rates) of oral OLZ versus non-OLZ treatments. ${ }^{12,13,19,20}$ Similarly, the greater room for improvement and potentially greater effectiveness of olanzapine may also explain why symptoms in non-OLZ patients improved to a greater extent relative to symptoms in OLZ patients when they were administered OLAI.

In terms of safety, there were no statistically significant differences in the percentages of non-OLZ-pretreated patients versus OLZ-pretreated patients with treatment-emergent adverse events in the short-term or long-term studies. In addition, the adverse events detected were similar to those described in the oral olanzapine Summary of Product Characteristics (SPC) and OLAI SPC. ${ }^{23,24}$ Serious adverse events were significantly more frequent in patients pretreated with oral OLZ than in those treated with non-OLZ in the long-term study. However, given the limited number of patients who experienced serious adverse events, these findings should be interpreted with caution. In addition, although the frequency of adverse events was similar in OLZ patients versus nonOLZ patients, mean extrapyramidal symptom scores tended to decrease to a greater extent in non-OLZ patients than in OLZ patients in both studies, reaching statistical significance for akathisia symptoms in the long-term study. From a clinical perspective, larger decreases in extrapyramidal symptom scores in non-OLZ patients versus OLZ patients are to be expected, given that olanzapine has a lower risk of extrapyramidal symptoms when compared with other antipsychotic medications. ${ }^{25-27}$ Also, the differences in these changes might be explained by the different baseline values for the pretreatment groups.

In addition, while the incidence of clinically significant changes in fasting glucose, fasting triglycerides, and total, high-density lipoprotein, and low-density lipoprotein cholesterol levels were similar between OLZ patients and nonOLZ patients in each study, a significantly greater number of patients treated with OLZ compared with non-OLZ patients in the short-term study reported potentially clinically significant weight gain $(\geq 7 \%)$. The latter result was unexpected because it is likely that at least some patients in the OLZ group would have experienced an increase in body weight before switching to OLAI, relative to non-OLZ patients, because greater weight gain has been reported during treatment with olanzapine compared with some other antipsychotics. ${ }^{28}$ Thus, in theory, after switching to OLAI, OLZ-pretreated patients should not experience significantly more increases in body weight when compared with non-OLZ-pretreated patients. In contrast, based on literature reports, non-OLZ-pretreated patients may have a greater risk of weight gain when exposed to olanzapine, regardless of the formulation used. ${ }^{28}$

Several limitations may affect these current analyses, so our findings should be interpreted with care. Firstly, because these were post hoc analyses, they should be considered exploratory. A prospective study design, if at all possible, could be a more ideal approach to compare the effects of switching from different antipsychotic medications on the effectiveness and safety of OLAI. This is particularly relevant for comparing changes over time as well as endpoint values between the two pretreatment groups, given that OLZ-pretreated and non-OLZ-pretreated patients often had different baseline values.

Secondly, our analyses were limited to a small number of patients. In particular, our analysis of the 8-week study was limited to only 12 patients in the OLZ group, which may be responsible for the lack of statistical significance with PANSS scores, despite trends towards lower values in the non-OLZ group versus the OLZ group. However, while 97 patients used oral olanzapine in the 8-week source study, only 12 of these patients were taking 
olanzapine as monotherapy. Exclusion of patients using additional non-OLZ antipsychotic medications from the OLZ group thus ensured that we could ascribe the results of the current post hoc analyses solely to OLZ, although the number of patients was limited by this.

Thirdly, the patients in our analyses had differing clinical profiles. Patients who switched to OLAI from any non-OLZ therapy were analyzed in one group per study, rather than being subdivided into individual groups per non-OLZ drug. Thus, potential differences in clinical outcomes between patients switching from different non-OLZ drugs were not detected. Another example of patient differences, which may have influenced safety and effectiveness outcomes, is exposure to different doses of OLAI (ie, $210 \mathrm{mg} / 2$ weeks, $300 \mathrm{mg} / 2$ weeks, and $405 \mathrm{mg} / 4$ weeks in the short-term study versus $150-405 \mathrm{mg} / 4$ weeks in the long-term study). Indeed, greater efficacy and larger changes in metabolic safety measures (eg, greater weight gain) have been reported at higher doses of OLAI. ${ }^{29}$

Fourthly, the short-term and long-term changes during treatment with OLAI were examined in two separate studies and in two different patient populations, rather than in one longitudinal investigation. As with the third limitation, differences between the two studies, which may have influenced safety and effectiveness outcomes, include exposure to different medications before each study and the different doses of OLAI used in each study. Hence, it was not possible to combine or directly compare the effectiveness and safety outcomes of the two studies, and the current analyses were performed separately per study.

\section{Conclusion}

These post hoc analyses suggest that patients switching from non-OLZ to OLAI did not experience lower tolerability or less effectiveness (measured by time to all-cause discontinuation, rates and reasons for discontinuation, and mean changes in PANSS and CGI-S scores) compared with patients switching from oral OLZ to OLAI. This was the case both with acutely ill patients (8-week OLAI treatment) and stabilized patients (2-year OLAI treatment). However, these findings should be interpreted with care, particularly due to the small sample sizes and differences in patients' clinical profiles.

\section{Author contributions}

$\mathrm{AC}, \mathrm{MC}, \mathrm{AS}, \mathrm{EA}$, and EP assisted with study design, interpretation of the study results, and manuscript preparation. AS and LB were responsible for data analysis and statistical consulting. All authors approved the final version of the submitted manuscript.

\section{Disclosure}

This publication was supported by Eli Lilly \& Co. All authors are full time employees of Eli Lilly \& Co. Michael Riley and Thomas Wagner from Trilogy Writing and Consulting $\mathrm{GmbH}$, Frankfurt, Germany, provided medical writing support on behalf of Eli Lilly \& Co.

\section{References}

1. Falkai P, Wobrock T, Lieberman J, et al. World Federation of Societies of Biological Psychiatry (WFSBP) guidelines for biological treatment of schizophrenia, part 2: long-term treatment of schizophrenia. World J Biol Psychiatry. 2006;7:5-40.

2. Kane JM, Leucht S, Carpenter D; Expert Consensus Panel for Optimizing Pharmacologic Treatment of Psychotic Disorders. The expert consensus guideline series. Optimizing pharmacologic treatment of psychotic disorders. Introduction: methods, commentary, and summary. J Clin Psychiatry. 2003;64 Suppl 12:S5-S19.

3. Nasrallah HA. The case for long-acting antipsychotic agents in the post-CATIE era. Acta Psychiatr Scand. 2007;115:260-267.

4. Kane JM. Strategies for improving compliance in treatment of schizophrenia by using a long-acting formulation of an antipsychotic: clinical studies. J Clin Psychiatry. 2003;64 Suppl 16:S34-S40.

5. Patel MX, Taylor M, David AS. Antipsychotic long-acting (depot) injections for the treatment of schizophrenia. Br J Psychiatry. 2009;195:S1-S57.

6. Taylor M, Ng KY. Should long-acting (depot) antipsychotics be used in early schizophrenia? A systematic review. Aust $N Z J$ Psychiatry. 2013;47:624-630.

7. Tiihonen J, Haukka J, Taylor M, Haddad PM, Patel MX, Korhonen P. A nationwide cohort study of oral and depot antipsychotics after first hospitalization for schizophrenia. Am J Psychiatry. 2011;168:603-609.

8. Lauriello J, Lambert T, Andersen S, Lin D, Taylor CC, McDonnell D. An 8-week, double-blind, randomized, placebo-controlled study of olanzapine long-acting injection in acutely ill patients with schizophrenia. J Clin Psychiatry. 2008;69:790-799.

9. Kane JM, Detke HC, Naber D, et al. Olanzapine long-acting injection: a 24-week, randomized, double-blind trial of maintenance treatment in patients with schizophrenia. Am J Psychiatry. 2010;167:181-189.

10. Detke H, Weiden PJ, Lambert T, et al. Olanzapine long-acting injection vs oral olanzapine in schizophrenia outpatients: a 2-year, randomized, open-label study. Eur Neuropsychopharmacol. 2010;20:S464.

11. ClinicalTrials.gov. Olanzapine pamoate depot versus oral olanzapine on treatment outcomes in outpatients with schizophrenia. Available from: http://clinicaltrials.gov/show/NCT00320489. Accessed January 31, 2013.

12. Lieberman JA, Stroup TS, McEvoy JP, et al; for the Clinical Antipsychotic Trials of Intervention Effectiveness (CATIE) Investigators. Effectiveness of antipsychotic drugs in patients with chronic schizophrenia. N Engl J Med. 2005;353:1209-1223.

13. Kahn RS, Fleischhacker WW, Boter H, et al; for EUFEST Study Group. Effectiveness of antipsychotic drugs in first-episode schizophrenia and schizophreniform disorder: an open randomised clinical trial. Lancet. 2008;371:1085-1097.

14. Ascher-Svanum H, Montgomery WS, McDonnell DP, Coleman KA, Feldman PD. Treatment-completion rates with olanzapine long-acting injection versus risperidone long-acting injection in a 12-month, openlabel treatment of schizophrenia: indirect, exploratory comparisons. Int J Gen Med. 2012;5:391-398.

15. Kay SR, Fiszbein A, Opler LA. The positive and negative syndrome scale (PANSS) for schizophrenia. Schizophr Bull. 1987;13:261-276. 
16. Guy W. ECDEU Assessment Manual for Psychopharmacology. Washington, DC: US Department of Health, Education and Welfare; 1976.

17. Barnes TR. A rating scale for drug-induced akathisia. Br J Psychiatry. 1989;154:672-676.

18. Simpson GM, Angus JW. A rating scale for extrapyramidal side effects. Acta Psychiatr Scand Suppl. 1970;212:11-19.

19. Tiihonen J, Wahlbeck K, Lönnqvist J, et al. Effectiveness of antipsychotic treatments in a nationwide cohort of patients in community care after first hospitalisation due to schizophrenia and schizoaffective disorder: observational follow-up study. BMJ. 2006;333:224

20. Beasley CM Jr, Stauffer VL, Liu-Seifert H, Taylor CC, Dunayevich E, Davis JM. All-cause treatment discontinuation in schizophrenia during treatment with olanzapine relative to other antipsychotics: an integrated analysis. J Clin Psychopharmacol. 2007;27:252-258.

21. Leucht S, Komossa K, Rummel-Kluge C, et al. A meta-analysis of head-to-head comparisons of second-generation antipsychotics in the treatment of schizophrenia. Am J Psychiatry. 2009;166:152-163.

22. Leucht S, Corves C, Arbter D, Engel RR, Li C, Davis JM. Secondgeneration versus first-generation antipsychotic drugs for schizophrenia: a meta-analysis. Lancet. 2009;373:31-41.

23. Olanzapine long-acting injection. Summary of Product Characteristics. July 11, 2012. Available from: http://www.medicines.org.uk/EMC/ medicine/21361/SPC/ZYPADHERA $+210+\mathrm{mg} \% 2 \mathrm{c}+300+\mathrm{mg} \% 2 \mathrm{c}+\mathrm{an}$ $\mathrm{d}+405+\mathrm{mg} \% 2 \mathrm{c}+$ powder+and+solvent + for+prolonged+release + suspe nsion+for+injection/. Accessed February 8, 2013.
24. Olanzapine. Summary of Product Characteristics. July 11, 2012. Available from: http://www.medicines.org.uk/EMC/medicine/614/ SPC/Zyprexa++2.5 mg\%2c+5 mg\%2c+7.5 mg\%2c+10 mg\%2c+ $15 \mathrm{mg} \% 2 \mathrm{c}++$ and $+20 \mathrm{mg}+$ coated+tablets. + Zyprexa+Velotab++ $5 \mathrm{mg} \% 2 \mathrm{c}+10 \mathrm{mg} \% 2 \mathrm{c}+15 \mathrm{mg} \% 2 \mathrm{c}++$ and $+20 \mathrm{mg}++$ orodispersible+tabl ets/. Accessed February 8, 2013.

25. Novick D, Haro JM, Bertsch J, Haddad PM. Incidence of extrapyramidal symptoms and tardive dyskinesia in schizophrenia: thirty-six-month results from the European schizophrenia outpatient health outcomes study. J Clin Psychopharmacol. 2010;30:531-540.

26. Komossa K, Rummel-Kluge C, Hunger H, et al. Olanzapine versus other atypical antipsychotics for schizophrenia. Cochrane Database Syst Rev. 2010;3:CD006654.

27. Krzystanek M, Krupka-Matuszczyk I. An open, large, 6-month naturalistic study of outcome in schizophrenic outpatients, treated with olanzapine. Hum Psychopharmacol. 2011;26:81-85.

28. Bushe CJ, Slooff CJ, Haddad PM, Karagianis JL. Weight change by baseline BMI from three-year observational data: findings from the Worldwide Schizophrenia Outpatient Health Outcomes Database. J Psychopharmacol. 2013;27:358-365.

29. Hill AL, Sun B, Karagianis JL, Watson SB, McDonnell DP. Dose-associated changes in safety and efficacy parameters observed in a 24-week maintenance trial of olanzapine long-acting injection in patients with schizophrenia. BMC Psychiatry. 2011;11:28.
Neuropsychiatric Disease and Treatment

\section{Publish your work in this journal}

Neuropsychiatric Disease and Treatment is an international, peerreviewed journal of clinical therapeutics and pharmacology focusing on concise rapid reporting of clinical or pre-clinical studies on a range of neuropsychiatric and neurological disorders. This journal is indexed on PubMed Central, the 'PsycINFO' database and CAS.

\section{Dovepress}

The manuscript management system is completely online and includes a very quick and fair peer-review system, which is all easy to use. Visit http://www.dovepress.com/testimonials.php to read real quotes from published authors. 